\title{
Pup Growth Rates and Breeding Female Weight Changes in Two Populations of Captive Bred Degus (Octodon degus), a Precocial Caviomorph Rodent
}

\author{
CV Long ${ }^{1}$ and LA Ebensperger ${ }^{2}$ \\ ${ }^{1}$ University of Loughborough, Loughborough, UK; ${ }^{2}$ Departamento de Ecología, Facultad de Ciencias Biológicas and CASEB, Pontificia Universidad \\ Católica de Chile, Santiago, Chile
}

\begin{abstract}
Contents
Caviomorph rodents are renowned for comparatively long gestations and producing relatively precocious offspring. The degu (Octodon degus) is one such caviomorph, originating in central Chile and providing communal pup care within wild groups. Reported are pup growth data for two populations of captive bred degus in Britain and Chile (representing wild populations), for the first time analysing pup development over the postpartum and weaning period in detail. Pups in both colonies were found to be similarly precocial at birth as assessed by open eyes and presence of full body hair. Degu pups in the British colonies put on weight at a rate of 2-3 g/day, while pups in the Chilean colonies put on weight at a rate of $1-2 \mathrm{~g} /$ day over the first 14 days. At birth, individual neonates weighed $5 \pm 1 \%$ of maternal mass for the British sample and $6 \pm 0.5 \%$ for the Chilean sample. Sexual dimorphism occurred in the weight and growth rates of pups in both samples, despite the lack of sexual dimorphism in adults of the species. Data for breeding female weight changes were also analysed, providing the first reported observations for this crucial period. Pregnant female weight gain was found to vary over the course of gestation, and post partum weight changes varied significantly between breeding females in accordance with litter size.
\end{abstract}

\section{Introduction}

The degu (Octodon degus) is a diurnal, social caviomorph rodent native to the semi-arid scrublands of central Chile. Degus (both in the wild and in captivity) are seasonal breeders (Ebensperger et al. 2002; Bozinovic et al. 2004; Ebensperger and Hurtado 2005); females begin oestrus in late autumn and pups are born in early spring (Bozinovic et al. 2004; Ebensperger and Hurtado 2005). In addition, female degus may be induced ovulators (Weir 1974), requiring presence of a male to begin oestrus. Female degus are pregnant for around 90 days (Weir 1974; Veloso and Kenagy 2005) and pups are born relatively precocious, being fully furred, having teeth and with eyes and ears open almost immediately after birth (Reynolds and Wright 1979). Average litter sizes contain $6 \pm 1$ pups (Ebensperger et al. 2002, 2007), although this can vary from only one pup to up to 12 pups per litter (C.V. Long, unpublished observations). Weaning of the pups takes 4-6 weeks (Kleiman 1974; Veloso and Kenagy 2005) and consists of three stages; early (days 5-8), middle (days 15-21) and late (days 26-40) (Veloso and Kenagy 2005). Newborn pups in colonies in the USA weigh around $14 \mathrm{~g}$ (Woods and Boraker 1975) and grow at a rate of $2 \mathrm{~g} /$ day (Reynolds and Wright 1979). The first solid food is eaten at day 6 (Reynolds and Wright 1979), although solid food can only be digested when the pups are 15 days old (Veloso and Kenagy 2005). Data from captive degus indicate that pups experience a delayed puberty, with females becoming sexually mature around 7 weeks and males at 12 weeks postpartum (Braun et al. 2003).

The use of the degu as a laboratory subject has grown over the last few decades due to its unique biological features; not only is the degu used as a diabetes model due to its unusual blood glucose regulation system (e.g. Nishi and Steiner 1990) but also as a diurnal model for circadian rhythm studies. Degus are able to re-entrain based on social cues alone (Goel and Lee 1997) to an extent that varies dependent on sex (Jechura et al. 2000). Recent findings suggest sex hormones are responsible for circadian development in the postpubescent degu (Hummer et al. 2007). Other areas of study frequently include cataract formation (e.g. Worgul and Rothstein 1975), social behaviour and group living (e.g. Ebensperger et al. 2004, 2007; Wilson 2004) and separation-induced stress during development (e.g. Poeggel et al. 1999).

It is widely believed that a small sample of wild degus was originally exported from Chile to North America in the 1950 s for diabetes research, and that this population is the genetic origin of the majority of captive degus today in Europe and the US. Both Weir (1974) and Reynolds and Wright (1979) suggested that degu pups born in captivity in Britain are less developed at birth (as indicated by a delayed opening of the eyes and poor fur coverage) than those born in captivity in the US, and that two phenotypes exist.

Here, the pup growth rates in two populations of captive-housed degus and breeding female weight changes over the breeding season were assessed. A sample of British degus in captive breeding colonies were monitored over a period of 36 months and a sample of captive 'wild' degus maintained in Chile were also monitored and the weight data for developing pups recorded. By observing eye openness and fur coverage at birth in both colonies, it was possible to assess precocity. Weight changes of breeding female degus in the British sample over the breeding season were also investigated, providing the first published data for this specific time period. Results from this study will provide a crucial reference point for future studies on the species to improve care and maintenance.

\section{Materials and Methods}

All research conducted as part of this study conformed to national and institutional guidelines for research on 
live mammals (permits 1894 and 2711 by the Servicio Agrícola y Ganadero).

\section{British animals}

A sample of juvenile and adult female degus $(n=5)$, kept in a private collection, and their litters $(n=9$; $\mathrm{n}_{\text {pups }}=37$ ) born over three years were used in this study. The number of pups in each litter ranged from 1 to 7; in this study 'pups' were defined as being aged 0 days up to 6 weeks old; at this age all pups were fully weaned and separated from the adults and sex-segregated at 6 weeks. The juveniles were defined as being aged between 7-58 weeks old during the study, with adults in the age range of 59 weeks up to 5 years. All degus had been bred in captivity for at least two traceable generations from eight original degus obtained from various private individuals around the UK, to minimize the chance of direct genetic relationship between British colony members.

\section{Wild animals}

A sample of captive adult female degus $(n=7)$, maintained at the Pontificia Universidad Católica de Chile, and their litters $\left(n=7 ; n_{\text {pups }}=37\right)$ born over 3 years were used in this study. These animals were direct descendents (2nd or 3rd generation) of wild degus trapped near Santiago and were therefore genetically representative of a wild population. The number of pups in each litter ranged from 4 to 6 .

\section{British degu housing and maintenance}

Breeding female degus were divided into two colonies with a maximum colony size of five adults. Colony 1 consisted of two original female littermates for years 1 and 2 of the study $\left(\mathrm{N}_{\text {adult }}=2\right)$ and $1 F_{1}$ daughter for year $3\left(\mathrm{~N}_{\text {adult }}=3\right)$; colony 2 consisted of three original female littermates for year $1\left(\mathrm{~N}_{\text {adult }}=3\right)$, plus $1 \mathrm{~F}_{1}$ daughter for year $2\left(\mathrm{~N}_{\text {adult }}=4\right)$, plus an additional $F_{1}$ daughter for year $3\left(\mathrm{~N}_{\text {adult }}=5\right)$. The original females in colony 1 and 2 were not directly related. During the breeding season (November-April) of years 1 and 2 of the study, one original, unrelated male from an all-male colony joined colony $1\left(\mathrm{~N}_{\mathrm{adult}}=3\right)$. Each colony was housed in a wire mesh cage of dimensions $45 \mathrm{~cm}$ wide $\times 75 \mathrm{~cm}$ long $\times 100 \mathrm{~cm}$ high. Although only female colonies were examined in this study, female colony enclosures were placed adjacent to male colony enclosures throughout the three years. During breeding, the selected female and a selected unrelated male were transferred to an open pen $(2 \mathrm{~m} \times 2 \mathrm{~m})$ for approximately half an hour during female oestrus to allow mating to occur (excepting colony 1 during years 1 and 2 when the male cohabited during the breeding season). Although all female degus in both colonies were involved in pup care, colony 1 bred communally (i.e. more than one litter was present in the colony) during years 1 and 2; colony 2 never bred communally and neither colony breed communally in year 3 . Colonies were not artificially lit but exposed to natural light with a seasonally varying photoperiod in accor- dance with British day length (approx. $13 \mathrm{~h} \mathrm{~L}: 11 \mathrm{~h} \mathrm{D}$ at latitude $52^{\circ} 38^{\prime} \mathrm{N}$ ). All degus were fed on a sugar-free hard feed mix designed for guinea pigs (fibre $10 \%$, protein $16 \%$, fat $3 \%$, ash $5 \%$, vitamin $\mathrm{C}$ included at $250 \mathrm{mg} / \mathrm{kg}$ ), supplied in a quantity of $10 \mathrm{~g}$ per juvenile/adult degu per day (each degu was fed from its own food dish) and $5 \mathrm{~g}$ per pup per day (pups in each colony were all fed from one large food dish at the same time as the juveniles/adults). All degus were also given free access to high quality meadow hay to enable them to forage throughout the day and to boost fibre intake, mimicking the dietary requirements of wild degus (Gutiérrez and Bozinovic 1998; Bozinovic et al. 2004). Fresh drinking water was provided ad libitum via a drinking bottle. Each colony cage had a large, solid metal running wheel permanently available for exercise; this was used by juveniles, adults and pups from 2 to 3 weeks old. Colonies were maintained at room temperature $\left(16-22^{\circ} \mathrm{C}\right)$.

\section{Wild degu housing and maintenance}

When 3 months of age, females were divided into colony pairings with either a full sister or an unrelated female. Each pair was housed in a clear polycarbonate rat cage of dimensions $45 \times 23 \times 21 \mathrm{~cm}$, and provided with ad libitum access to drinking water and commercial rabbit pellet hard feed. During the breeding season each year, an unrelated male was placed inside the female colony enclosure for 60 days to allow mating to occur. Pregnant females were then transferred to a separate area into a clear acrylic tank 7-10 days prior to the expected delivery date. Pregnant females were housed either in isolation (cage dimensions $61.5 \times 31.5$ $\times 40.5 \mathrm{~cm}$ ) or with a non-breeding female (cage dimensions $61.5 \times 62 \times 40.5 \mathrm{~cm})$. All animals were exposed to a natural photoperiod and temperature (approx $12 \mathrm{~h} \quad \mathrm{~L}: 12 \mathrm{~h} \quad \mathrm{D}$ at latitude $33^{\circ} 28^{\prime} \mathrm{S}$; $13.4-24.9^{\circ} \mathrm{C}$ ). During pregnancy, food was provided at $80-90 \%$ of the energy requirements of an adult lactating female degu.

\section{British degu data collection}

All adult and juvenile degus (pregnant and nonpregnant) were weighed regularly each month on walkon weighing scales accurate to $1 \mathrm{~g}$ throughout the duration of the study and scales were calibrated with a $200 \mathrm{~g}$ fixed-mass weight prior to every weighing event. Weighing was performed at the start of each month at the same time of day to avoid bias due to daily weight fluctuations. Maternal females were also weighed daily from parturition (a few hours after birth) until pups were 2 weeks old. Weighing of pups took place in the presence of the mother, where pups were gently removed from the nest for the minimum amount of time necessary to record weights before being returned to the nest. This was performed to avoid stressing the pups in compliance with findings by Poeggel et al. (1999) and Helmeke et al. (2001). Pups were weighed daily from birth, one at a time, on scales accurate to $1 \mathrm{~g}$ until the pups reached 2 weeks old, when each pup was weighed weekly until weaned at 6 weeks. As a measure of 
precocity, the number of pups with open eyes a few hours after birth was recorded.

\section{Wild degu data collection}

Maternal female degus and their pups were weighed every other day from parturition (within $24 \mathrm{~h}$ of birth) until the pups were 30 days old, on scales accurate to $0.5 \mathrm{~g}$. Pups were weighed individually and all weights were taken at the same time of day, again to avoid bias due to possible daily weight fluctuations. The number of pups with open eyes was also recorded on the day of birth.

\section{Data analysis}

Data were analysed by means of a repeated analysis of covariance model, using the GLM module of STATISTICA 5.1 (StatSoft, Inc., Tulsa, OK, USA). For the British sample, this was performed by examining variables in the growth of pups from birth up to day 14 postpartum, to identify any short-term effects before the pups began the weaning process. For pup data up to day 14, "pup weight' was entered as the dependent variable, 'maternal relatedness' (full sister, $F_{1}$ daughter, unrelated) and 'pup sex' (male, female) were examined as independent variables with 'age post partum' as a covariate. The weight of the mother was chosen as a second covariate, as maternal weight has previously been found to be a significant predictor of pup growth (Ebensperger et al. 2007). In all cases, the 'time period' covariate was also examined as an independent variable to assess the effects of time over growth rate. Weight variations between litters in each sample (Inter-litter pup weights) were statistically compared using 'pup weight' as the dependent variable and 'litter number' as the independent variable with 'age post partum' and 'litter mother' as covariates. The effect of relatedness was examined across litters for the breeding females in the British sample only; genetic relatedness between communally breeding wild degus was previously found not to influence the growth of pups or female mass during lactation (Ebensperger et al. 2007).

\section{Results}

Female degus were found to come into oestrus periodically between November-January, which was determined by visual examination for vaginal perforation [female degus, like other hystricomorphs, have an external vaginal membrane which becomes perforate during oestrus (Weir 1974)]. Individual neonates on average weighed $5 \pm 1 \%$ of maternal mass for the British sample and $6 \pm 0.5 \%$ of maternal mass for the wild sample.

\section{Pups aged 0-14 days}

Figure 2 depicts the pup growth and rate of weight change data for both samples over the first 14 days postpartum. All pups in the British and wild samples were born fully furred and with open eyes (Fig. 1). Interlitter pup weights between breeding females were found

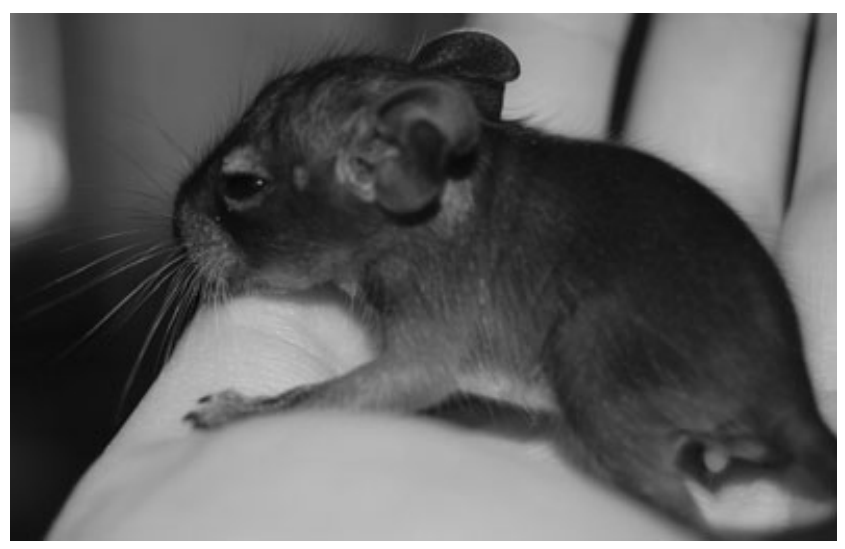

Fig. 1. Newborn degu pup (0 days) from the British sample, taken a few hours after birth. The pup is fully furred and has open eyes

to vary significantly, both in the wild $\left(\mathrm{F}_{[6,288]}=39.43\right.$; $\mathrm{p}<0.005)$ and in British $\left(\mathrm{F}_{[4,549]}=96.01 ; \mathrm{p}<0.005\right)$ samples. To investigate potential effects of relatedness between breeding females on pup growth, this was analysed in further detail for the British sample. Relatedness between litter mothers did not explain the variation of inter-litter pup growth, with litters from sister siblings having significant pup weight differences (between $07 \mathrm{~F}$ and $08 \mathrm{~F} \quad \mathrm{~F}_{[1,207]}=7.76 ; \mathrm{p}<0.05$, between $04 \mathrm{~F}$ and $\left.05 \mathrm{~F} \quad \mathrm{~F}_{[1,252]}=7.27 ; \mathrm{p}<0.005\right)$. When subsequent litters from the same female were analysed, inter-litter pup weights also varied significantly (three litters of $05 \mathrm{~F} \quad \mathrm{~F}_{[2,236]}=251.02$; $\mathrm{p}<0.005)$. Pup sex had a statistically significant effect on pup weight, with male pups weighing significantly more than female pups $\left(\mathrm{F}_{[1,758]}=56.50 ; \mathrm{p}<0.005\right)$ for both samples. Pup sex was also found to significantly affect the rate of pup weight change; males were found to have a significantly higher rate of weight gain than females, for both samples $\left(\mathrm{F}_{[1,473]}=7.89 ; \mathrm{p}<0.05\right)$. 'British' pups put on weight at a rate of $2-3 \mathrm{~g} /$ day, whilst pups in the wild sample put on weight at a rate of 1-2 g/day over the first 14 days (Fig. 2c,d). As expected, day postpartum was found to significantly influence both pup weight $\left(\mathrm{F}_{[14,836]}=130.36 ; \mathrm{p}<0.005\right)$ and the rate of pup weight change $\left(\mathrm{F}_{[6,511]}=12.05 ; \mathrm{p}<0.005\right)$ for both samples over the first 14 days.

\section{Pups aged 0-6 weeks}

Figure 3 depicts the mean pup growth and rate of weight change data for pups in both samples over the first 6 weeks postpartum. Again, week postpartum was found to significantly influence pup mean weight $\left(\mathrm{F}_{[6,5]}=19.45 ; \mathrm{p}<0.005\right)$ for both samples over the first 6 weeks. However, the postpartum period up to week 6 was found not to have a significant effect on the rate of weight change $\left(\mathrm{F}_{[5,4]}=1.58\right)($ Fig. $3 \mathrm{c}, \mathrm{d})$.

\section{Breeding females}

Figure 4 depicts weight changes over the breeding season for breeding females in the British colony. Figure 5 depicts breeding female postpartum weight 
(a)

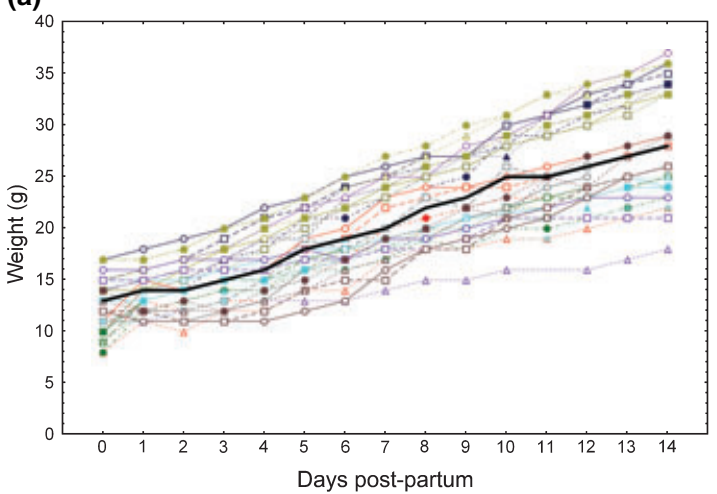

(c)

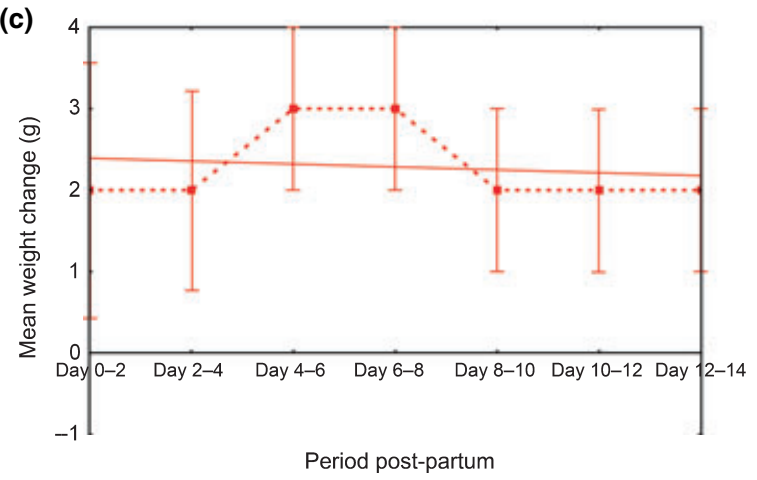

(b)

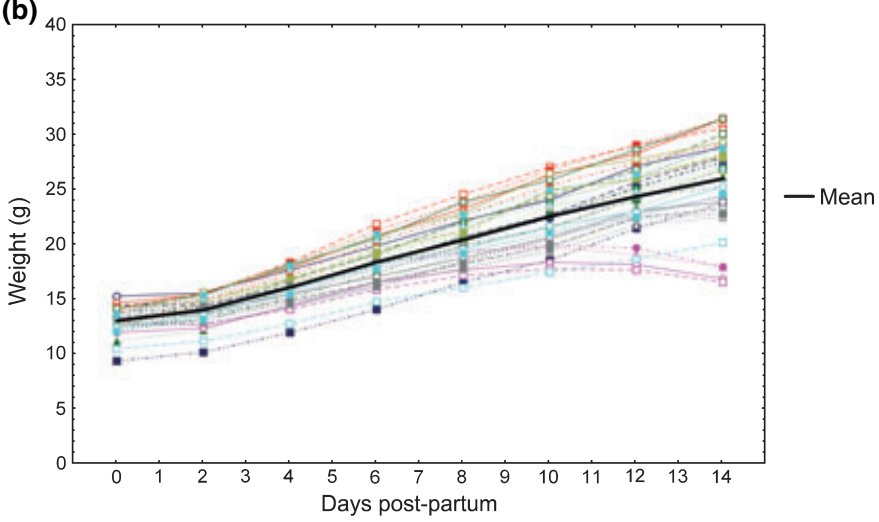

(d)

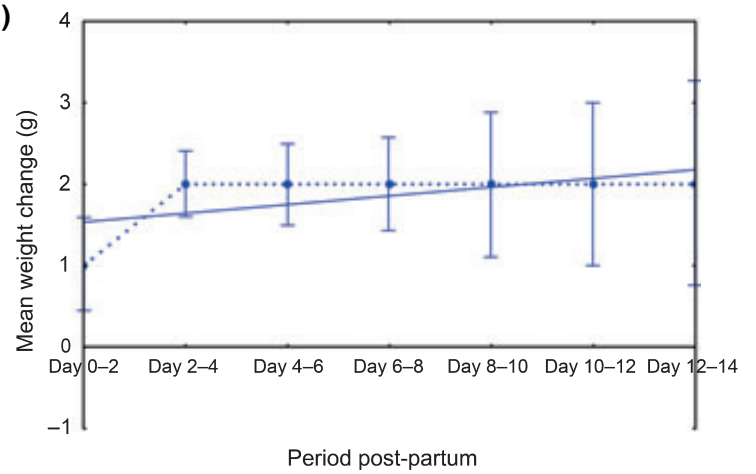

Fig. 2. Degu pup weight data for the wild and British samples, from birth up to day 14. (a) Weight data for all pups in the British sample. (b) Weight data for all pups in the wild sample. (c) Pup weight change data for the British sample with error bars and fit line. (d) Pup weight change data for the wild sample with error bars and fit line

changes from parturition to day 14 of lactation for both samples. Maternal postpartum weight change varied significantly between individual litters, both between females in the wild sample $\left(\mathrm{F}_{[6,48]}=31.50 ; \mathrm{p}<0.005\right)$ and between females in the British sample $\left(\mathrm{F}_{[8,116]}=152.49 ; \mathrm{p}<0.005\right)$. Day post partum was found not to have a significant effect on maternal weight change over the first 14 days for females in both samples $\left(\mathrm{F}_{[14,167]}=0.97\right)$.

\section{Discussion}

\section{Pup growth}

Reynolds and Wright (1979) suggested the possibility that different phenotypes exist between degu pups born in captivity in Britain and those born in captivity in America, based on differences in precocity as judged by delayed eye opening; no such differences were observed in the British degus studied here. Precocity did not seem to differ markedly between the wild and British samples; all pups in the wild degu sample were born with eyes open during years 2 and 3 of the study (the pups in year 1 did not have this feature recorded). Species born with open eyes have previously been found to have more advanced cerebellar development (Sánchez-Villagra and Sultan 2002), which is a useful indicator of precocity. All pups in the British degu sample were also born with eyes open across all
3 years of the study (Fig. 1). This therefore suggests that pups in the 'British' colony of Weir (1974), which had closed eyes at birth that did not open until day 23 postpartum, may only have been representative of the British degu population at the time of study. Another key point that may have been mistaken for degu pups being 'poorly furred' is that neonates retain a downy, infantile coat until they are 1-2 weeks old (Rosen 1974; C.V. Long, unpublished observations). This fur has attributes which allow the pups to retain body heat at a saving of 7.78 calories $/{ }^{\circ} \mathrm{C} / \mathrm{h}$ (Rosen 1974), as they are unable to thermoregulate until the age of 8 days.

For the degus in this study, the fact that genetically related sister females had significantly different pup weights and that even the pup weights between litters of the same female differed significantly (i.e. there was phenotypic plasticity within samples) suggests that genetic makeup is likely to be a lesser factor in pup growth as compared with maternal weight. This point is specifically highlighted by the litter of the female W305 in the wild sample, where all pups demonstrated atypical weight loss over days 10-14 post partum, which correlated with sudden weight loss in the mother during this time. Dietary conditions are likely to play an important role in provision of milk for pup growth during lactation; a lactating female will convert food eaten almost immediately into milk (Veloso and Kenagy 2005). Pups in the wild and British samples had similar 

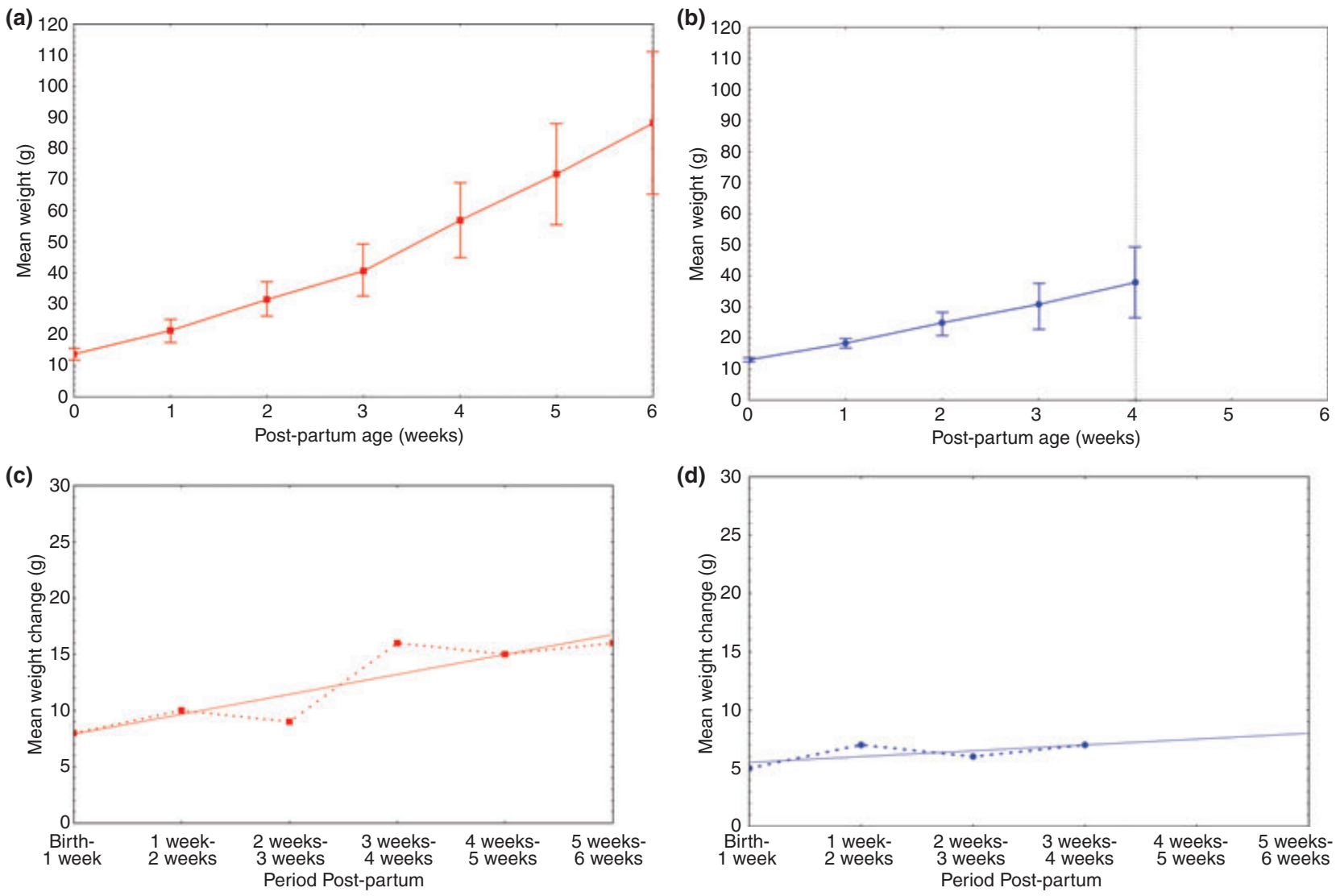

Fig. 3. Degu pup mean weight data for the wild and British samples, weekly weights from birth up to week 6 . Note that data for the wild sample were unavailable after week 4 as this is when weaning occurred. (a) Mean pup weight data for the British sample with error bars. (b) Mean pup weight data for the wild sample with error bars (dotted line indicates when weaning occurred). (c) Pup weight change data for the British sample in weekly increments with fit line. (d) Pup weight change data for the wild sample in weekly increments with fit line

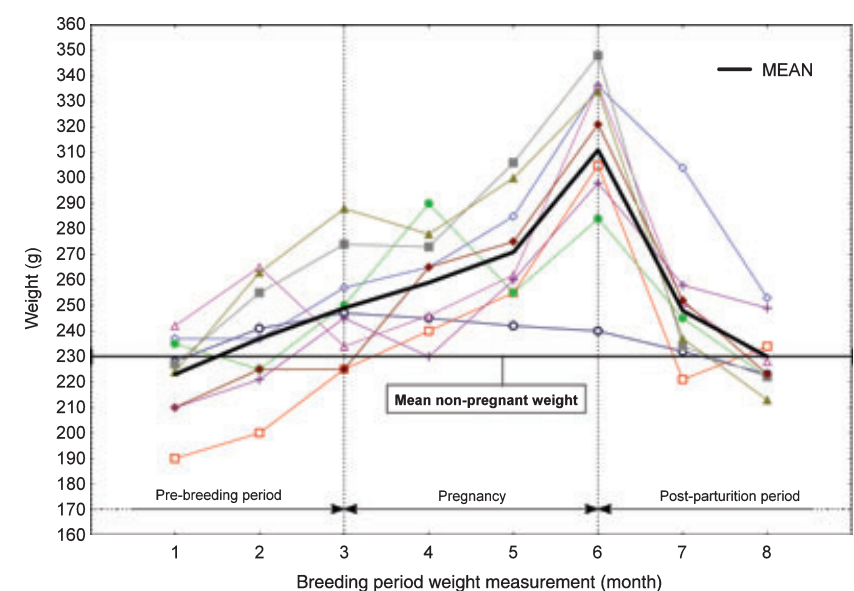

Fig. 4. Monthly weights for the breeding females in the British sample over an 8-month period over the breeding season, divided into the pre-breeding period, pregnancy and post-parturition period. The line at $230 \mathrm{~g}$ indicates the mean non-pregnant (fully adult) weight for all the females in the sample

mean birth weight values to those given by Reynolds and Wright (1979) (14.6 g). Rosen (1974) reports that the average weight of wild-born degu pups at 8 days old is $20 \mathrm{~g}$, which correlates well with the "wild' data in this study. A weight said to be a key threshold in degu pup development is $24-25 \mathrm{~g}$, as this corresponds to a rapid increase in thermoregulatory ability at an ambient temperature of $16.9^{\circ} \mathrm{C}$ (Rosen 1974). It can be speculated that reaching this weight is of more importance in cooler environments, which may partly explain why pups in the British sample reached this key weight, on average, within 10 days postpartum, while the 'wild' pups did not do so until the age of 2 weeks (Fig. 2). As the British colonies were maintained at a range of $16-22^{\circ} \mathrm{C}$ and the wild colonies at $13.4-24.9^{\circ} \mathrm{C}$, this is unlikely to be the case (although the wild sample was subjected to higher temperatures at times than the British sample).

The average pup birth mass expressed as a percentage of mother's postpartum mass can be compared with another caviomorph species with precocious young, the greater guinea pig, Cavia magna. At 6 and 5\% ('wild' and 'British' pups respectively), individual degu pups express a much lower value than that of both wild and captive cavy pups, at $18 \%$ and $14 \%$ of maternal mass respectively (Kraus et al. 2005). Cavies, however, have a much smaller litter size of only 1-3 pups, which would allow for a larger relative mass allocation per neonate. Values for both samples of degu pups were similar to the previously reported value of $5.6 \%$ of maternal mass (Nowak 1999).

It is interesting to note the finding that male degu pups were significantly heavier and put on weight at a significantly higher rate than female pups over the first 14 days postpartum. The reason for this remains 

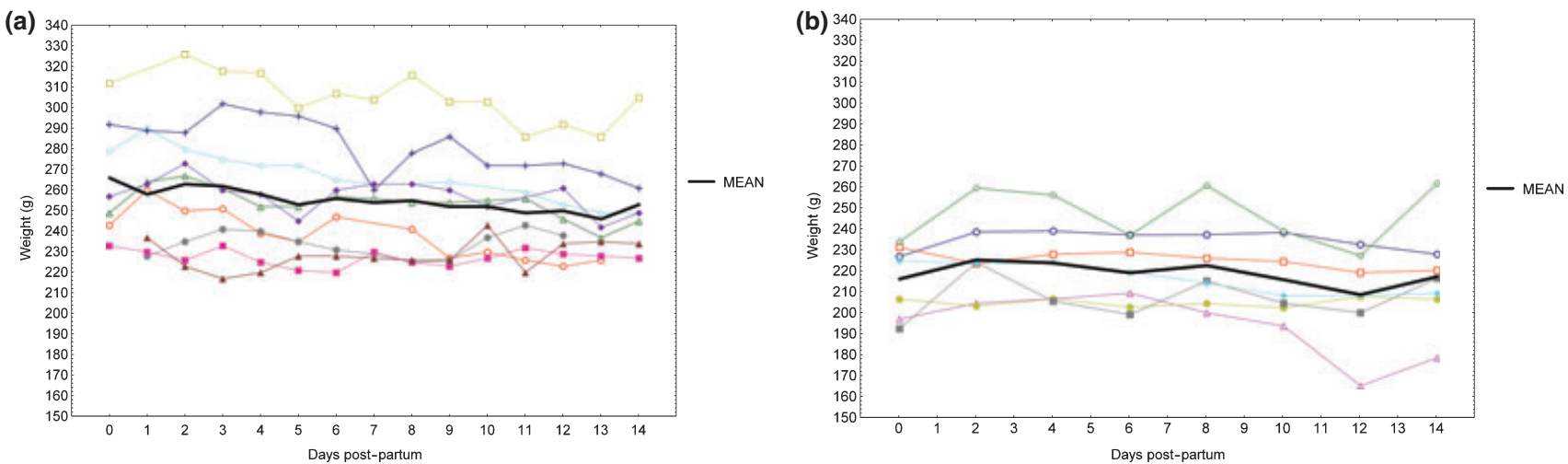

Fig. 5. Breeding female postpartum weight data for the period between parturition and day 14 of lactation. (a) Female weight data for the British sample. (b) Female weight data for the wild sample

unclear, particularly as other hystricomorphs such as the Cape porcupine Hystrix africaeaustralis do not demonstrate markedly different growth rates between the sexes (van Aarde 1987). However, similar traits have been reported in a study by Timon and Eisen (1970) in postweaned mice, where it was suggested that the sexgrowth difference was as a result of physiological differences in the efficiency of tissue growth. If this were true for degus, it is possible male pups produce new tissue more efficiently than female pups to reduce the time to sexual maturity, as there is a marked delay in puberty between male and female degus. The growth rates of wild and captive female guinea pigs are also known to decrease at a greater rate than that of males (Kraus et al. 2005), although this is thought to be linked to the larger body size of male cavies, which is not obvious in degus. However, the sexual dimorphic growth rates observed may well be linked to the sexual dimorphism of certain circadian features found in male and female degus a few months after puberty, which suggest sexual differentiation within the central nervous system (Hummer et al. 2007).

Figure 3 demonstrates a marked increase in pup growth rates, between weeks 2-3 and 3-4 postpartum, for pups in the British sample (although not for pups in the wild sample). A possible explanation is that by this age, pups have begun to eat and rely more on solid food to obtain energy for growth. The carbohydrate content of the milk decreases significantly from early to late lactation (pups have a high energy requirement early on) (Veloso and Kenagy 2005). As food was provided specifically for the pups in the British sample, this may explain why pups in the wild sample did not show a similar rate increase during this time. In addition, lactating females will consume more food to cope with energy demands, if available, during early lactation (Veloso and Bozinovic 2000), so providing more food during this time could boost pup growth and development. The initial high energy investment may also explain why the time period had a significant effect on pup rate of weight change over the first 14 days postpartum, but not over the full 6 weeks.

The fact that housing conditions such as litter size and number of adult degus present in the colonies was not constant was not considered to affect results. The previous findings by Ebensperger et al. (2007) demonstrated that female degu 'nesting condition' (rearing pups in isolation, with a non-breeding female, or communally) had no effect on pup weights or the postpartum weight changes of the mother.

\section{Breeding female weight changes}

As shown in Fig. 4, the mean value for British breeding female degu weight was found to rise steadily from the start of pregnancy up until the month prior to parturition, when a sharp increase in weight gain was observed. It is hypothesized that this rapid increase in weight corresponds to the sudden growth rate increase of pups during the last 3 weeks of pregnancy (degus have a markedly slow foetal growth rate during early pregnancy (Roberts and Perry 1974). This is associated with the sudden increase in abdominal size of the female, and also due to the onset of lactation. On average, pregnant females were found to gain weight up to $75.5 \pm 7.3 \%$ above non-pregnant weight. Interestingly, breeding females were also found, on average, to put on weight the month before pregnancy occurred, which could correlate with possible weight changes during breeding season. Such weight changes may be related to hormonal changes in the females at this time of year, similar to those seen in male degus (SotoGamboa 2005). For instance, it has previously been found that oestrogen and progesterone have marked effects on female degu body temperature and activity levels during oestrus (Labyak and Lee 1995). Weir (1974) reported a mean maternal weight (immediately after parturition) of $250 \mathrm{~g}$; this was found to be well below the mean maternal weight in the 'British' sample of this study.

The finding that maternal weight varied significantly between litters in both samples (including that several litters in the British sample were produced by sister sibling littermates) indicates that there is not likely to be a strong genetic component to maternal postpartum weight changes. The significant variation between maternal postpartum weights may be explained by the size (number of pups) of the litter and hence the relative 
energy invested in that litter. Alternatively, individual degus may have different rates of metabolism which would affect weight loss after birth. Veloso and Bozinovic (2000) noted that energy allocation during lactation in the degu does not follow that of other precocial rodents, and found a positive correlation between lactating female degu resting metabolic rate and litter mass and size. As maternal postpartum weight is not significantly altered over the first 14 days of lactation, it may be hypothesized that maternal weight requires a longer time period to return to a mean nonpregnant level. Figure 4 shows that although there is a large change between the mean weight at parturition and that at one month postpartum, weight may not be lost linearly over this time, which may well correlate with lactation and weaning.

In conclusion, degu pups in the captive wild and British sample populations studied here did not differ markedly in precocity at day 0 . Pups demonstrated growth at a mean rate of $2 \mathrm{~g}$ per day over the first 14 days and were found to differ significantly in weight and growth rate between the sexes. At birth, neonates' maternal mass percentage was similar for both populations. Weight gain of pregnant females was found to vary over the course of gestation, and postpartum weight changes were found to typically vary significantly between females in accordance with litter size.

\section{Author contributions}

C.V. Long - designed study, collected weight data for the British sample, prepared manuscript and analysed data. L.A. Ebensperger collected weight data for the Chilean sample, provided support and feedback for manuscript revisions and data analysis.

\section{References}

van Aarde RJ, 1987: Pre- and postnatal growth of the Cape porcupine Hystrix africaeaustralis. J Zool 211, 2533.

Bozinovic F, Bacigalupe L, Vasquez R, Visser H, Veloso C, Kenagy G, 2004: Cost of living in free-ranging degus (Octodon degus): Seasonal dynamics of energy expenditure. Comp Biochem Physiol A 137, 597-604.

Braun K, Kremz P, Wetzel W, Wagner T, Poeggel G, 2003: Influence of parental deprivation on the behavioural development in Octodon degus: Modulation by maternal vocalizations. Dev Psychobiol 42, 237-245.

Ebensperger LA, Hurtado MJ, 2005: Seasonal changes in the time budget of degus, Octodon degus. Behaviour 142, 91-112.

Ebensperger LA, Veloso C, Wallen P, 2002: Do female degus communally nest and nurse their pups?. Ethology 20, 143-146.

Ebensperger LA, Hurtado MJ, Soto-Gamboa M, Lacey EA, Chang AT, 2004: Communal nesting and kinship in degus (Octodon degus). Naturwissenschaften 91, 1028-1042.

Ebensperger LA, Hurtado MJ, León C, 2007: An examination of the consequences of communal versus solitary breeding on maternal condition and the early postnatal growth and survival of degu, Octodon degus, pups. Anim Behav 73, 185-194.

Goel N, Lee TM, 1997: Social cues modulate free-running circadian activity rhythms in the diurnal rodent, Octodon degus. Am J Physiol Regul Integr Comp Physiol 273, 797-804.
Gutiérrez J, Bozinovic F, 1998: Diet selection in captivity by a generalist herbivorous rodent Octodon degus from the Chilean costal desert. J Arid Environ 39, 601607.

Helmeke C, Ovtscharoff W, Poeggel G, Braun K, 2001: Juvenile emotional experience alters synaptic inputs on pyramidal neurons in the anterior cingulate cortex. Cereb Cortex 11, 717-727.

Hummer DL, Jechura TJ, Mahoney MM, Lee TM, 2007: Gonadal hormone effects on entrained and free-running circadian activity rhythms in the developing diurnal rodent Octodon degus. Am J Physiol Regul Integr Comp Physiol 292, 586-597.

Jechura TJ, Walsh JM, Lee TM, 2000: Testicular hormones modulate circadian rhythms of the diurnal rodent, Octodon degus. Horm Behav 38, 243-249.

Kleiman DG (1974) Patterns of behaviour in hystricomorph rodents. Symp Zool Soc Lond 34: 171-209. In: Rowlands IW, Weir BJ (eds), The Biology of Hystricomorph Rodents. Academic Press Inc, London.

Kraus C, Trillmich F, Künkele J, 2005: Reproduction and growth in a precocial small mammal, Cavia magna. J Mammal 86, 763-772.

Labyak SE, Lee TM, 1995: Estrus- and steroid- induced changes in circadian rhythms in a diurnal rodent, Octodon degus. Physiol Behav 58, 573-585.

Nishi M, Steiner DF, 1990: Cloning of complementary DNAs encoding islet amyloid polypeptide, insulin, and glucagon precursors from a New World rodent, the degu, Octodon degus. Mol Endocrinol 4, 1192-1198.

Nowak RM, 1999: Walker's Mammals of the World, 6th edn. Vol. 2. The Johns Hopkins University Press, Maryland, pp. 2015.

Poeggel G, Lange E, Hase C, Metzger M, Gulyaeva N, Braun K, 1999: Maternal separation and early social depravation in Octodon degus: quantitative changes of nicotinamide adenine dinucleotide phosphate-diaphorase-reactive neurons in the prefrontal cortex and nucleus accumbens. Neuroscience 94, 497-504.

Reynolds T, Wright J, 1979: Early postnatal physical and behavioural development of degus (Octodon degus). Lab Anim (NY) 13, 93-99.

Roberts CM, Perry JS, 1974; Hystricomorph embryology. Symp Zool Soc Lond 34: 333-360. In: Rowlands IW, Weir BJ (eds), The Biology of Hystricomorph Rodents. Academic Press Inc, London.

Rosen R, 1974: Ontogeny of the Homeothermic Response in Microtus pennsylvanicus and Octodon degus. Unpublished MS thesis, University of Vermont, Burlington, pp. 1-69.

Sánchez-Villagra MR, Sultan F, 2002: The cerebellum at birth in Therian mammals, with special reference to rodents. Brain Behav Evol 59, 101-113.

Soto-Gamboa M, 2005: Free and total testosterone levels in field males of Octodon degus (Rodentia, Octodontidae): Accuracy of the hormonal regulation of behavior. Rev Chil Hist Nat 78, 229-238.

Timon VM, Eisen EJ, 1970: Comparisons of ad libitum and restricted feeding of mice selected and unselected for postweaning gain. I. Growth, feed consumption and feed efficiency. Genetics 64, 41-57.

Veloso C, Bozinovic F, 2000: Effect of food quality on the energetics of reproduction in a precocial rodent, Octodon degus. J Mamm 81, 971-978.

Veloso C, Kenagy G, 2005: Temporal dynamics of milk composition of the precocial caviomorph Octodon degus (Rodentia: Octodontidae). Rev Chil Hist Nat 78, $247-252$. 
Weir BJ, 1974: Reproductive characteristics of hystricomorph rodents. Symp Zool Soc Lond 34: 265-301. In: Rowlands IW, Weir BJ (eds), The Biology of Hystricomorph Rodents. Academic Press Inc, London.

Wilson SC, 2004: Contact-promoting behavior, social development, and relationship with parents in sibling juvenile degus (Octodon degus). Dev Psychobiol 15, 257-268.

Woods C, Boraker D, 1975: Octodon degus. Mammalian Species 67, 1-5.
Worgul BV, Rothstein H, 1975: Congenital cataracts associated with disorganized meridional rows in a new laboratory animal: the degu (Octodon degus). Biomedicine 23, 1-4.

Submitted: 5 Apr 2009

Author's address (for correspondence): Chole V Long, University of Loughborough, Loughborough, Leicestershire, LE11 3TU, UK. E-mail: degutopia@btinternet.com 